\title{
Demand for and supply of out of hours care from general practitioners in England and Scotland: observational study based on routinely collected data
}

\author{
Chris Salisbury, Marialena Trivella, Stephen Bruster
}

Division of Primary
Health Care,
University of
Bristol, Canynge
Hall, Bristol
BS8 2PR
Chris Salisbury
consultant senior
lecturer
ICRF Medical
Statistics Group,
Institute of Health
Sciences,
Headington,
Oxford OX3 7LF
Marialena Trivella
medical statistician
Picker Europe,
County Mark
House, London
W1R 6LP
Stephen Bruster
survey manager
Correspondence to:
C Salisbury
c.salisbury@
bristol.ac.uk

BMJ 2000;320:618-21

\begin{abstract}
Objectives To determine the level of demand and supply of out of hours care from a nationally representative sample of general practice cooperatives.

Design Observational study based on routinely collected data on telephone calls, patient population data from general practices, and information about cooperatives from interviews with managers. Setting 20 cooperatives in England and Scotland selected after stratification by region and by size. Subjects 899657 out of hours telephone calls over 12 months.

Main outcome measures Numbers and age and sex specific rates of calls; variation in demand and activity in relation to characteristics of the population; timing of calls; proportion of patients consulting at home, at a primary care centre, or on the telephone; response times; hospital admission rates.

Results The out of hours call rate (excluding bank holidays) was 159 calls per 1000 patients/year, with rates in children aged under 5 years four times higher than for adults. Little variation occurred by day of the week or seasonally. Cooperatives in Scotland experienced higher demand than those in England. Patients living in deprived areas made $70 \%$ more calls than those in non-deprived areas, but this had little effect on the overall variation in demand. $45.4 \%$ (408 407) of calls were handled by telephone advice, $23.6 \%$ (212 550) by a home visit, and 29.8\% (267 663) at a centre. Cooperatives responded to $60 \%$ of calls within 30 minutes and to $83 \%$ within one hour. Hospital admission followed 5.5\% (30 743/554 179) of out of hours calls ( 8 admissions per 1000 patients/year).

Conclusions This project provides national baseline data for the planning of services and the analysis of future changes.
\end{abstract}

\section{Introduction}

The provision of care by general practitioners outside normal surgery hours has been revolutionised in the United Kingdom in recent years, and this process will continue with the expansion of the telephone helpline NHS Direct to cover the whole of Great Britain. ${ }^{1}$ No reliable national information exists, however, about the demand for out of hours care. Previous data come mainly from studies of deputising services, ${ }^{23}$ which underestimate demand because many general practitioners only use them at certain times, ${ }^{4}$ or from individual practices, ${ }^{5-8}$ which may not be representative. Many studies have been based on rates of claims for night visit fees, ${ }^{9-12}$ but only a small proportion of out of hours telephone calls are made at night and many out of hours calls are dealt with on the telephone and do not result in visits. ${ }^{13}$ Studies that have included telephone consultations have been local and small scale, ${ }^{6814-17}$ and underrecording of calls has been a further problem. ${ }^{18}$ Previous research has shown wide variation in demand, but it is difficult to compare work carried out in different years, different areas, and using different methodologies.

The growth of general practice cooperatives offers an opportunity to address these difficulties, as cooperatives provide out of hours care throughout the United Kingdom, and many record all calls electronically. Several evaluations of individual cooperatives have been published, showing considerable variation in their activity. ${ }^{19}{ }^{20}$ Little information has been available about the population covered by these cooperatives, preventing an investigation of how the variation in response relates to local demand.

A better understanding of the demand for out of hours care is important in order to plan services, particularly NHS Direct. As demand for health care is related to supply, accurate baseline information is essential to measure the effects of continuing change in organisation. Information about the supply of care by representative cooperatives, and how this varies in different settings, is important for setting benchmarks for clinical governance. In particular, the impact of cooperatives on the number of emergency admissions to hospital has important implications for secondary care services. We aimed to acquire such information by analysing out of hours calls made to a sample of representative cooperatives.

\section{Method}

We analysed data from all out of hours calls made to 20 representative cooperatives using Adastra management software over one year. This software is used by more than 100 cooperatives and deputising services providing care for more than half of the UK population.

\section{Selection of cooperatives}

Eight cooperatives using Adastra software recorded the postcodes of callers. As postcodes can be matched to underprivileged area scores ${ }^{21}$ we included all of these cooperatives in the study to show the number of calls from deprived areas. A further 12 cooperatives were randomly selected after stratification by region (southern England, the Midlands, northern England, and Scotland) and by size (more or fewer than 100 members). We selected eight cooperatives from southern England, and four from each of the other regions - this reflected the greater number of cooperatives and population density in the south. No cooperatives in Wales or Northern Ireland used Adastra. To recruit 20 cooperatives, we had to approach 23 (response rate 87\%). 
Table 1 Age and sex specific rates (per 1000 patients/year) of out of hours calls based on 707198 calls to 16 cooperatives

\begin{tabular}{|c|c|c|c|c|c|c|}
\hline \multirow{2}{*}{$\begin{array}{l}\text { Age group } \\
\text { (years) }\end{array}$} & \multicolumn{3}{|c|}{ Males } & \multicolumn{3}{|c|}{ Females } \\
\hline & No of calls & Population & Rate $(95 \%$ confidence interval) & No of calls & Population & Rate $(95 \%$ confidence interval) \\
\hline $0-4$ & 93151 & 135307 & 688 (684 to 693) & 80192 & 129127 & 621 (617 to 625) \\
\hline $5-14$ & 46743 & 302622 & 154 (153 to 156$)$ & 43650 & 287407 & $152(150$ to 153$)$ \\
\hline $15-24$ & 19937 & 267784 & 74 (73 to 75$)$ & 42444 & 261434 & 162 (161 to 164$)$ \\
\hline $25-44$ & 53323 & 697888 & 76 (76 to 77$)$ & 99641 & 685588 & 145 (144 to 146$)$ \\
\hline $45-64$ & 38175 & 570488 & 67 (66 to 68$)$ & 51651 & 570343 & 91 (90 to 91) \\
\hline $65-74$ & 22693 & 191639 & 118 (117 to 120$)$ & 26696 & 221905 & 120 (119 to 122) \\
\hline$\geqslant 75$ & 32897 & 128015 & 257 (254 to 260$)$ & 56005 & 228308 & 245 (243 to 247$)$ \\
\hline All ages & 306919 & 2293743 & 134 (133 to 134) & 400279 & 2384112 & 168 (167 to 168) \\
\hline
\end{tabular}

Data on age or sex, or both, were missing in $35767 / 742965$ (4.8\%) of calls.

\section{Collection of calls data}

With Adastra software, calls from patients are entered by receptionists directly on to the system as they are received-all calls that were passed to a doctor or nurse for assessment are included in this study. Some general enquiries are dealt with by receptionists alone and these are not necessarily recorded. They may include cases where a receptionist advises a patient to call a dentist or ambulance instead of the cooperative.

A program was written to extract anonymised details of calls received from 1 September 1997 to 31 August 1998, including the patient's age, sex, postcode, date and time of call, site and timing of consultation, and details of hospital admissions.

\section{Analysis}

Data were analysed in SPSS for Windows. "Out of hours" was defined as 1900 to 0700 on weekdays and from 1200 onwards on Saturdays at weekends. We excluded bank holidays from the main analyses because cooperatives' opening times varied, but rates including bank holidays were calculated for a subset of cooperatives that were open throughout. We compared rates of calls at different cooperatives by direct age standardisation using the UK population as a reference.

Where cooperatives recorded patients' postcodes, we matched these to underprivileged area scores and we classified scores of $>30$ as deprived. In calculating the total number of calls from deprived areas and nondeprived areas, we made adjustment proportionally for each cooperative to allow for calls with missing postcodes.

\section{Patient populations}

We asked every practice belonging to each cooperative to provide details of its list size, the age and sex distribution of its patients, the number of patients attracting deprivation payments, and the number of rural practice units that it was paid. Two reminders were sent to practices. In most cases we obtained a total list size for nonresponding practices; in other cases we multiplied the number of partners in the practice by the average list size for the local health authority. We assumed that non-responding practices had patient populations with the same demographic characteristics as responding practices in their cooperative. If less than $70 \%$ of practices belonging to a cooperative responded, the cooperative was excluded from calculations of rates of calls. We performed a one way sensitivity analysis based on non-responding practices having a mean list size $50 \%$ larger or smaller than that assumed.

\section{Organisation of cooperatives}

A semistructured interview was conducted with the manager at each cooperative. This reviewed the ways in which calls were received and entered and the factors relating to the locality, structure, or organisation of the cooperative that would influence the interpretation of the analysis of calls.

\section{Results}

Of 1099401 calls recorded over the year, 899657 fell within the defined out of hours period and 37046 occurred during bank holidays between 0700 and 1900 .

At three cooperatives less than $70 \%$ of member practices provided demographic details of patients, and a further cooperative transferred calls to a deputising service after midnight; four cooperatives were therefore excluded from rate calculations. The average response rate from practices at the remaining 16 cooperatives to our request for population details was $88 \%$ (range $71 \%$ to $100 \%$ ).

\section{Demand for out of hours care}

The age and sex specific rates of out of hours calls are shown in table 1 . The overall out of hours call rate (excluding bank holidays) was 159 calls per 1000 patients/year (95\% confidence interval 158.5 to 159.2 ; range 127 to 299 ). The sensitivity analysis showed that the rate would lie between 157 and 161 calls per 1000 patients/year if the estimated list sizes of nonresponding practices varied by up to $50 \%$.

At the 12 cooperatives that were open during bank holidays the overall call rate was 144 (143.8 to 144.6) excluding the bank holiday opening times and 151 (150.8 to 151.6) including these times.

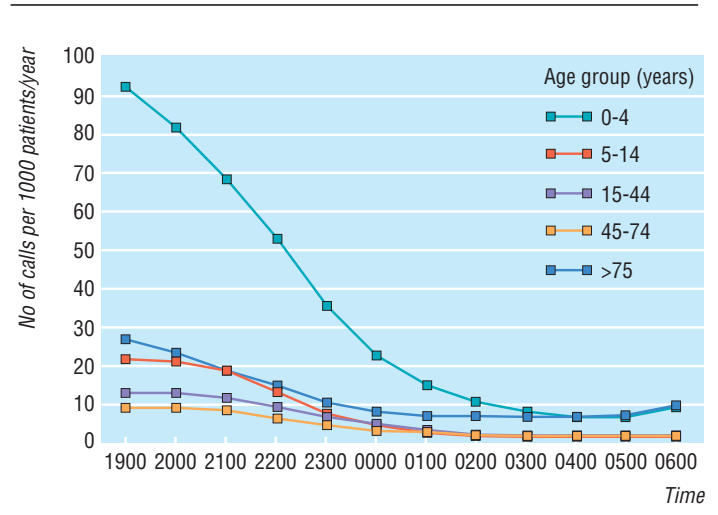

Fig 1 Rate of calls at different times by age groups 


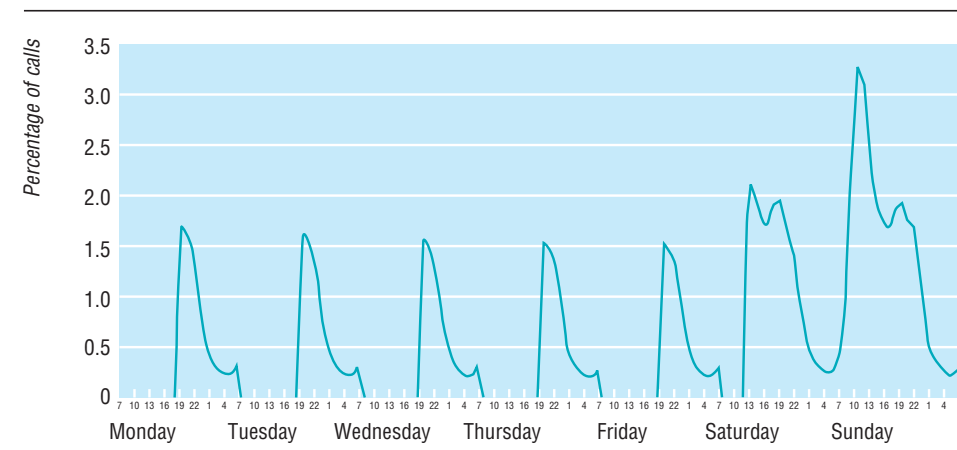

Fig 2 Distribution of out of hours calls over one week based on 888167 calls to 19/20 cooperatives (the excluded cooperative closed at midnight)

Table 2 Annual call rates per 1000 population for four cooperatives that covered deprived populations

\begin{tabular}{lccccc} 
& \multicolumn{3}{c}{ Cooperative } & \\
\cline { 2 - 5 } & A & B & C & D & Overall (95\% CI) \\
\hline Rate per 1000 population in deprived areas & 286 & 201 & 267 & 193 & 239 (235 to 242) \\
\hline Rate per 1000 population in non-deprived areas & 190 & 126 & 177 & 131 & 141 (141 to 142) \\
\hline Overall rate & 198 & 127 & 179 & 133 & 144 (143 to 144) \\
\hline
\end{tabular}

$\mathrm{Cl}=$ confidence interval.

The pattern of calls by time was similar for all age groups, with most calls being made in the early evening, although most of these evening calls related to infants (fig 1). There was little variation by day of the week, although nights at weekends were slightly busier than weekday nights. The distribution of calls over a whole week showed that the peak demand occurred on Sunday mornings (fig 2). Little seasonal variation occurred, with a slightly increased number of calls between November and March and fewest calls in September and October.

The cooperatives in Scotland experienced higher demand than those in England (standardised rate 221 $v 145$ calls per 1000 patients/year) (fig 3). We could not show any relation between the rate of out of hours calls at different cooperatives and the age structure of the patient population or the proportion living in rural or deprived areas.

For five cooperatives we obtained details of the underprivileged area scores of callers and calculated the proportion of patients living in deprived areas. For these five cooperatives the average proportion of calls for which details of scores were available was $81 \%$ (range $67 \%$ to $99 \%$ ). One of these cooperatives did not cover any deprived areas, leaving data from four cooperatives for analysis. The rate of calls from deprived areas was $70 \%$ higher than that from non-deprived areas (table 2).

\section{Response of cooperatives}

Almost half (408 407; 45.4\%) of the out of hours calls to all cooperatives (outside bank holidays) were handled by telephone advice from a doctor or nurse; a quarter $(212550 ; 23.6 \%$ ) by home visits; and 29.8\% (267 663) by the patient attending a primary care centre. For 11033 (1.2\%) calls there were other outcomes, and data were missing for four calls. The telephone advice rate varied between cooperatives from $26 \%$ to $66 \%$, and the proportion of patients attending a centre varied from $10 \%$ to $57 \%$. The site of consultations was related to the age of the patient, with $53.5 \%$
(89 566/167 430) of calls from patients aged over 65 years leading to a home visit.

Cooperatives responded to $60 \%$ of all calls within 30 minutes and $83 \%$ within one hour. The median response time for a home visit was 39 minutes, with $70 \%$ of visits being made within one hour and $92 \%$ within two hours.

\section{Hospital admissions}

Eleven cooperatives recorded details of all referrals for hospital admission. Admission followed 5.5\% (30 743/ 554179 ) of out of hours calls to these cooperatives. This represents a rate of $8.2(95 \%$ confidence interval 8.1 to 8.3 ) admissions per 1000 patients/year. The age specific out of hours admission rate increased from 3 per 1000 patients/year in young people aged 5-14 years to 21 per 1000 patients/year in patients aged over 75 years. The percentage of calls leading to admission was related to time, from a minimum of $4 \%$ of calls during the day at weekends to a peak of $9 \%$ between 0200 and 0600 .

\section{Discussion}

The information that we have provided here about the demand and supply of out of hours care by general practitioners is based on a much larger and more representative sample of calls than has been previously available. The sample of cooperatives in this project is not random because we initially included those that recorded patients' postcodes and because cooperatives using Adastra software might be a selected group. The sample was balanced, however, by size and by region and was drawn from cooperatives covering most of England and Scotland.

One potential weakness of this study is the assumptions about missing data used to estimate patient populations. The sensitivity analysis shows that this is unlikely to affect our results significantly. A further weakness concerns potential variability between cooperatives in the discretion they allow receptionists to redirect callers to another agency without recording the fact.

The overall calls rate is slightly lower than previously reported. $^{6-8161820}$ This may represent a

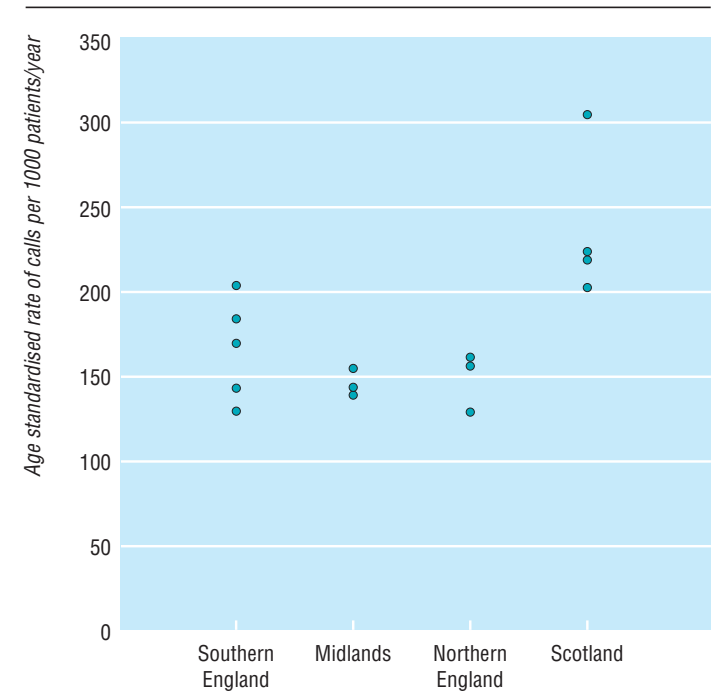

Fig 3 Rates of calls to cooperatives in different regions 
change with time or the fact that earlier studies were conducted in small and often atypical (usually urban) areas. Two recent studies reporting higher rates both came from Scotland, ${ }^{16}{ }^{20}$ and our results also show high rates of calls at Scottish cooperatives.

The finding that patients living in deprived areas contacted a cooperative far more often than patients living in non-deprived areas supports earlier research.$^{15}$ In the analysis of overall demand, however, the variation in call rates between different cooperatives could not be accounted for by local demographic features (age structure, deprivation, and rurality). These inconsistent findings may occur because the small proportion of patients living in deprived areas at each cooperative would have little effect on overall call rates.

A survey of cooperatives conducted in 1996 and based on self reported data of unknown reliability suggested wide variation in the proportion of patients being offered consultations at home, at a centre, or over the telephone..$^{22}$ Our project, which used standardised data collection, has confirmed this variation and has shown a higher level of telephone advice than reported in the earlier survey. The consequences of these widely varying policies in terms of clinical outcomes, patient satisfaction, and cost effectiveness deserve further study.

The pattern of response by cooperatives in England and Scotland is now similar to that observed in Denmark after its reorganisation of out of hours services in $1992 .{ }^{23}$ The total demand for out of hours services, however, seems to be two to three times greater in Denmark, ${ }^{24}$ Finland, ${ }^{25}$ and the Netherlands ${ }^{26}$ than in England and Scotland. International comparisons should be interpreted cautiously because of varying definitions of the out of hours period and differences in health service organisation.

The findings about hospital admissions suggest that a system of care based on cooperatives would not lead to higher admission rates than would a care system based on practice rotas. ${ }^{27}$ The findings about response times suggest that cooperatives provide a rapid response to most calls-considerably faster than that reported in studies of deputising services. ${ }^{19}{ }^{27}$ The greater accessibility of out of hours care, reinforced by the expansion of NHS Direct, ${ }^{28}$ may lead to an increase in demand for care. This project provides reliable national baseline data from which to test this hypothesis.

We thank the doctors and staff at the 20 participating cooperatives and Adastra Software, especially Randolph Burt, for their help and support throughout this project. We also thank Debbie Hart and Mike Muirhead for matching patients' postcodes to underprivileged area scores for England and Scotland respectively; Lothian, Lanarkshire, and Ayrshire and Arran Health Boards for providing data about practices; Connie Junghans for entering data about patient populations; and Tim Peters for statistical advice. The views and opinions expressec are those of the authors and do not necessarily reflect those of the NHS Executive.

Contributors: CS was the grant holder, designed and led the study, contributed to the analysis, and wrote the paper. Coordination of the project, interviews with cooperative managers, and analysis of data were conducted initially by SB and then by MT. All authors saw and approved the final version of the paper. CS is the guarantor.

Funding: This study was funded by the London regional office of the NHS Executive.

Competing interests: None declared.

1 Pencheon D. NHS Direct: managing demand. BMJ 1998;316:215-6.

2 Bain DJ. Deputising services: the Portsmouth experience. BMJ 1984; 289:471-3.

\section{What is already known on this topic}

Accurate information about the demand for and supply of out of hours care by general practitioners has been lacking

Much research has centred on night visits (only a small proportion of all out of hours calls) or atypical areas, with little information about the patient population

\section{What this study adds}

The rate of out of hours telephone calls to 20 nationally representative general practice cooperatives is 159 per 1000 population a year

Demand seems higher in Scotland than in England and much higher in deprived areas

Only 1 in 20 calls led to hospital admission

Call rates and cooperatives' responses varied with the age and sex of patients

Baseline data are now available for assessing the effect of further changes in service organisation, such as NHS Direct

3 Dixon RA, Williams BT. Twelve months of deputising: 100000 patient contacts with eighteen services. BMJ 1977;1:560-3.

4 Salisbury C. Evaluation of a general practice out of hours cooperative: a questionnaire survey of general practitioners. BMJ 1997;314:1598-9.

5 Carlisle RD, Johnstone SP, Pearson JC. Relation between night visit rates and deprivation measures in one general practice. BMJ 1993;306:1383-5.

6 Pitts J, Whitby M. Out of hours workload of a suburban general practice: deprivation or expectation. $B M J$ 1990;300:1113-5.

7 Robinson G. Night visits in general practice. BMJ 1993;306:1068.

8 Livingstone AE, Jewell JA, Robson J. Twenty four hour care in inner cities: two years' out of hours workload in east London general practice. BM 1989;299:368-70

9 Majeed FA, Cook DG, Hilton S, Poloniecki J, Hagen A. Annual night visiting rates in 129 general practices in one family health services authority: association with patient and general practice characteristics. $\mathrm{Br} J \mathrm{Gen}$ Pract 1995;45:531-5.

10 Whynes D, Baines D. Explaining variations in the frequency of night visits in general practice. Fam Pract 1996;13:174-8.

11 Salisbury C. Visiting through the night. BMJ 1993;306:762-4

12 Baker D, Klein R. Explaining outputs of primary health care: population and practice factors. BMJ 1991;303:225-9

13 Marsh GN, Horne RA, Channing DM. A study of telephone advice in managing out-of-hours calls. J R. Coll Gen Pract 1987:37:301-4.

14 McCarthy M, Bollam M. Telephone advice for out of hours calls in general practice. BrJ Gen Pract 1990;40:19-21.

15 Carlisle R, Groom LM, Avery AJ, Boot D, Earwicker S. Relation of out of hours activity by general practice and accident and emergency services with deprivation in Nottingham: longitudinal survey. BMJ 1998;316:520-3.

16 Heaney DJ, Gorman DR. Auditing out-of-hours primary medical care. Health Bull Edin 1996;54:495-8.

17 Soler M, Dowers A, Jones RB. Out of hours work in primary care: audit of an urban co-operative deputising service. Health Bull Edin 1991:49:40-7.

18 Brogan C, Pickard D, Gray A, Fairman S, Hill A. The use of out of hours services: a cross sectional survey. BMJ 1998;316:524-7.

19 Salisbury C. Observational study of a general practice out of hours cooperative: measures of activity. $B M J$ 1997;314:182-6.

20 Bain J, Gerrard L, Russell A, Locke R, Baird V. The Dundee out of hours cooperative: preliminary outcomes for the first year of operation. $\mathrm{BrJ} \mathrm{Gen}$ Pract 1997;47:573-4.

21 Jarman B. Identification of underprivileged areas. BMJ 1983;286:1705-9

22 Jessopp L, Beck I, Hollins L, Shipman C, Reynolds M, Dale J. Changing the pattern out of hours: a survey of general practice cooperatives. BM 1997;314:199-200

23 Christensen MB, Olesen F. Out of hours service in Denmark: evaluation five years after reform. $B M J$ 1998;316:1502-5.

24 Hansen BL, Munck A. Out-of-hours service in Denmark: the effect of a structural change. Br J Gen Pract 1998;48:1497-9.

25 Vehvilainen AT, Takala JK. Where have all the back pains gone? Changes in the reasons for requiring out-of-hours medical care from a centralized primary care centre after changing to a list system. Fam Pract 1996;13:373-6.

26 Van Duijn NP, van Weert HCPM, Scholte D, Bindels PJE. Out of hours: primary care clinic or hospital emergency department? Eur J Gen Pract 1998;4:69-73.

27 Cragg DK, McKinley RK, Roland MO, Campbell SM, Van F, Hastings $\mathrm{AM}$, et al. Comparison of out of hours care provided by patients' own general practitioners and commercial deputising services: a randomised general practitioners and commercial deputising services: a
controlled trial. I: The process of care. BMJ 1997;314:187-9.

28 Beecham L. NHS Direct will cover England by end of 2000. BMJ 1999;318:1097.

(Accepted 29 November 1999) 